\title{
BMJ Open Impact of metoprolol standard dosing pathway in Chinese patients with acute coronary syndrome: protocol for a multicentre prospective study
}

Dandan Li, Wei Dong, Yuqi Liu, Jingjing Wang, Yang Mu, Hao Zhou, Jing Wang, Shanshan Zhou, Yundai Chen

To cite: Li D, Dong W, Liu Y, et al. Impact of metoprolol standard dosing pathway in Chinese patients with acute coronary syndrome: protocol for a multicentre prospective study. BMJ Open 2019;9:e031972. doi:10.1136/ bmjopen-2019-031972

- Prepublication history for this paper is available online. To view these files please visit the journal online (http://dx.doi org/10.1136/bmjopen-2019031972).

Received 30 May 2019 Revised 08 0ctober 2019 Accepted 09 0ctober 2019
Check for updates

(C) Author(s) (or their employer(s)) 2019. Re-use permitted under CC BY-NC. No commercial re-use. See rights and permissions. Published by BMJ.

Department of Cardiology, Chinese PLA General Hospital, Beijing, China

Correspondence to

Dr Yundai Chen;

cyundai@vip.163.com

\section{ABSTRACT}

Introduction Metoprolol is the most frequently used $\beta$-receptor blockers; however, the prescribed dose in China is far less than the recommended doses in the guidelines. Based on the Chinese and International guidelines and the Chinese clinical practice, we are conducting this study (NCT03413410) to test the feasibility and tolerability of the metoprolol optimal dosing pathway by observing the percentage of patients achieving target dose in Chinese acute coronary syndrome (ACS) patients during hospitalisation.

Methods and analysis A total of about 1000 patients aged $\geq 18$ years, hospitalised for ACS will be enrolled from $~ 15$ hospital sites in China between February 2018 and April 2019. The percentage of patients achieving the target metoprolol dosage at discharge is the primary endpoint. The secondary endpoints included the following: mean heart rate (HR) and blood pressure (BP) of the patients who have achieved target dose at discharge and during the follow-up period, percentage of patients experiencing bradycardia ( $\mathrm{HR}<50$ beats/min), hypotension (BP $<90 / 60 \mathrm{~mm} \mathrm{Hg}$ ) and drug-related temporary heart failure worsening during hospitalisation and 1 month after discharge, respectively. We will also assess the proportion of patients reporting metoprolol-related adverse events and the leading causes for metoprolol discontinuation. Ethics and dissemination The study protocol has been approved by the Ethics committee of the Chinese PLA General Hospital (number: S2017-112-01). Study findings will be disseminated through presentations at national and international conferences and submitted for publications in peer-reviewed journals.

Trial registration number ClinicalTrials.gov registry (NCT03413410).

\section{INTRODUCTION}

Acute coronary syndrome (ACS) is one of the most common type of cardiovascular disease characterised by a spectrum of clinical symptoms ranging from ST-segment elevation myocardial infarction (STEMI) to non-STsegment elevation myocardial infarction and unstable angina. ${ }^{1}$ ACS is a subtype of coronary heart disease (CHD) that is associated

\section{Strengths and limitations of this study}

- The results of this study will provide an insight into the optimal dosing of metoprolol in acute coronary syndrome (ACS) patients during hospitalisation and after discharge.

- This research may aid the treating physicians to appropriately manage their patients and also to reinforce the key quality goals.

- This study will increase the utilisation of $\beta$-blockers which has proven benefits in reducing mortality in ACS patients.

Safety and tolerability of metoprolol will be observed.

with high risk of mortality. In China, there has been a rapid increase in the number of patients with ACS mainly owing to an increase in ageing population as well as the prevalence of cardiovascular risk factors. ${ }^{2}$ According to Markov computer simulation model, the incidence of CHD is reported to cross 2.5 million events per year by 2030 , which is $50 \%$ more than that reported in $2010 .^{3}$

$\beta$-receptor blockers are the principal drugs prescribed in acute myocardial infarction. According to the American Heart Association (ACCF/AHA) guidelines, oral $\beta$-blockers are class I recommendation for symptoms onset within the first 24 hours and intravenous $\beta$-receptor blockers are class II indication for hypertensive patients or those who have ongoing ischaemia. ${ }^{45}$ Further, the 2013 ACCF/AHA recommends oral (level of evidence B) $\beta$-blockers within 24hours of disease onset for the management of STEMI and further suggests in continuing $\beta$-receptor blockers during hospitalisation and after discharge (level of evidence B). ${ }^{4}$ Evidences from previous studies have reported reduced mortality and other cardiovascular events following use of $\beta$-blockers in ACS patients. ${ }^{6-8}$ The earlier study by Hjalmarson et al reported 
an overall mortality reduction rate of $36 \%$ in patients who treated with $200 \mathrm{mg}$ /day metoprolol from hospital admission and continued for 3 months. ${ }^{6}$ Similarly, the recent study by de Matos Soeiro has also reported a significant reduction in mortality and major cardiovascular events in patients treated with oral $\beta$-receptor blockers compared with placebo group. ${ }^{8}$

The use of $\beta$-receptor blockers not only improves the clinical outcomes in ACS patients but also reduces the cost of the relevant treatment significantly. ${ }^{9}$ Based on the superior efficacy of $\beta$-receptor blockers in terms of reduced mortality and other adverse cardiological events, the Chinese as well as international guidelines recommend $\beta$-receptor blockers as the first line therapy for treatment of ACS patients. ${ }^{45}$ As per the Chinese Cardiology society, patients with ACS should take $\beta$-receptor blockers within 24 hours of symptom onset starting from a lower dose and slowly escalating the dose. ${ }^{10}$

In cases of good drug tolerance, long-acting controlled-release preparation of corresponding dose can be prescribed after 2-3 days. Oral metoprolol is the most commonly prescribed $\beta$-receptor blocker in patients with ACS. It is usually given at an initial dose of $25-50 \mathrm{mg} / 6-12$ hours and after 2-3 days it is switched to metoprolol tartrate two times per day or metoprolol succinate once a day. Further, if the drug is well-tolerated it can be titrated to $200 \mathrm{mg} /$ day. ${ }^{4}$ Recently, an investigation indicated that $190 \mathrm{mg}$ metoprolol succinate was welltolerated for Chinese patients. ${ }^{11}$

Although $\beta$-receptor blockers are always recommended in all the international guidelines, how to maintain the use of $\beta$-receptor blockers for a long term and balance the appropriate dose is one practical question for clinicians and patients. Among the 221874 AMI patients included in the 2011 China Peace survey, only $61.8 \%$ were treated with $\beta$-blockers. It was also noticed that metoprolol was the most commonly prescribed $\beta$-blocker $(91.5 \%)$; however, the dosages were often below than those recommended in Western countries and in the guidelines. ${ }^{12}$

Insufficient attention paid by clinicians to heart rate (HR) control, lack of an operational standardisation process of its use and concern about adverse reactions caused by high dosage are all possible causes of insufficient use of $\beta$-blockers in Chinese population. ${ }^{13}$ As there are not much studies reporting the use of metoprolol in ACS patients in China and China's ACS guidelines do not give a clear clinical pathway for metoprolol, we conduct this study to test the feasibility and tolerability of the metoprolol optimal dosing pathway by observing the percentage of Chinese ACS patients achieving target dose following the pathway during hospitalisation and following discharge.

The safety and tolerability of metoprolol will be explored in this study through observation of the proportion of patients with bradycardia, hypotension and transient exacerbation of cardiac function after administration of the drug using standard method summarised in the guidelines.

\section{METHODS AND ANALYSIS Study design}

This is a multi-centre, prospective, open label, single-arm interventional study that will recruit all the new ACS patients admitted to the hospital. A full list of the 15 participating centres is shown in table 1 . All the 15 centres are public hospitals which have research ethics committees and clinical trial qualifications. The number of patients and conditions of the centres will meet the requirements. All the centres will have highly trained and

\begin{tabular}{ll}
\hline Table 1 & The 15 study participating centres \\
\hline Code & Participating hospitals \\
\hline 1 & Chinese PLA General Hospital, Beijing, China \\
\hline 2 & Beijing Friendship Hospital, Capital Medical University, Beijing, China \\
3 & The First Affiliated Hospital of Dalian Medical University, Dalian, China \\
\hline 4 & Sino-Japanese Friendship Hospital of Jilin University, Changchun, China \\
\hline 5 & Affiliated Zhongshan Hospital of Dalian University, Dalian, China \\
6 & Nanjing Drum Tower Hospital, The Affiliated Hospital of Nanjing University Medical School, Nanjing, China \\
\hline 8 & The Affiliated Hospital of Qingdao University, Qingdao, China \\
\hline 9 & East Hospital of Qingdao Municipal Hospital (Group), Qingdao, China \\
10 & Shanxi Cardiovascular Hospital, Taiyuan, China \\
11 & Shanghai Sixth People's Hospital, Shanghai, China \\
12 & The Affiliated Hospital of Northwest University, Xi'an No.3 Hospital, Xi'an, China \\
13 & The First People's Hospital of Yunnan Province, Kunming, China \\
14 & The First Hospital of Jilin University, Changchun, China \\
15 & Beijing Luhe Hospital, Capital Medical University, Beijing, China \\
\hline
\end{tabular}


Visit X: dose titration (multiple titrations allowed)

Visit 1: enrolment

. $\mid$
During hospital
Visit 2

\begin{tabular}{|l|l|}
\multicolumn{1}{|c|}{ Dose titration } & \\
\hline & Discharge \\
Informed consent \\
Inclusion/exclusion criteria \\
Baseline information collection
\end{tabular}

Visit $\mathrm{X}$ : dose titration (multiple titrations allowed)

Visit 4

(telephone visit)
Visit 3

(telephone visit)

\section{Four weeks after discharge}

Heart rate, blood pressure, heart failure temperate worsening, concomitant medication, other treatment

Figure 1 Study design with visit schedules of patients.

experienced personnel. All the patients after registration will be assessed for the parameters specified on admission. We will obtain signed informed consent form (ICF) from all eligible patients or their guardian/legal representative before any study specific procedures are performed. Specified demographic information and other clinical data will be collected for the patients enrolled according to the case report form. The patients will be enrolled consecutively from February 2018 and the recruitment will end in April 2019 or until a total of 1000 patients are included cumulatively. Figure 1 elaborates on the study procedure including the visit schedule of patients.

\section{Study participants}

Participants will be recruited from the study sites if they fulfil the following inclusion criteria: age $\geq 18$ years, male or female patients hospitalised due to ACS. Patients will be excluded if they have been involved in another clinical trial in the last 3 months; have been using $\beta$-agonists on a continuous or intermittent basis; have cardiological adverse events such as cardiac shock, unstable heart failure, hypotension (blood pressure (BP) $<90 / 60 \mathrm{~mm} \mathrm{Hg}$ ) or bradycardia (HR <50 beats/min), sick sinus syndrome, II III atrioventricular block, Killip $>$ II, suspected acute myocardial infarction with $\mathrm{HR}<45$ beats $/ \mathrm{min}, \mathrm{P}-\mathrm{R}$ interval $>0.24 \mathrm{~s}$ or systolic $\mathrm{BP}<100 \mathrm{~mm}$ $\mathrm{Hg}$; patients allergic or contraindicated for metoprolol; cancer patients; patients at a risk of developing cardiogenic shock; pregnant or lactating women and are unable to understand the study procedures or unable/reluctant to participate as judged by the investigator will be excluded. The study will be performed in accordance with the ethical principles of the Declaration of Helsinki and will also be consistent with the International Conference on Harmonization and Good Clinical Practice.
The patients will be thoroughly informed regarding the details of the study. The signed and dated ICF by the patient or his/her guardian/legal representative will be obtained at the first visit. The patients should take metoprolol within 24 hours after admission. Baseline information including any concomitant medications will be recorded in the trial process chart, figure 2.

The patients will also be informed of their independence to discontinue participation at any time. The patients may withdraw from the study due to unnatural death (due to accident or violent); patient's wish to discontinue; inability to complete hospitalisation for any reason; or loss of follow-up. The patient may also be withdrawn from the study prematurely for other reasons at discretion of the investigator. All the patients who are withdrawn from the study prematurely should complete all the tests and procedures before the discharge. The reason for premature withdrawal should be noted in the case report form and original medical record. If the patient is withdrawn from the study for adverse event (AE), he/she should be followed up and given corresponding treatment. Further, the study centre can be terminated early if serious adverse event (SAE) or any other safety issue occurs during the study and the ethics committee should be informed promptly and formally.

\section{Treatment}

According to the ACCF/AHA guidelines, ${ }^{4}$ patients with ACS who do not have contraindications should use $\beta$-blockers and achieve the maximum dose that can be tolerated. The clinical signs of the patients will be evaluated by the investigators before administration of $\beta$-blockers within 48 hours after enrolment. The evaluation parameters include: rest $\mathrm{HR} \geq 45$ beats $/ \mathrm{min}$ and without symptomatic bradycardia, systolic BP $\geq 100 \mathrm{~mm}$ 


\begin{tabular}{|c|c|c|c|c|c|}
\hline $\begin{array}{c}\text { Type of Data to be } \\
\text { Collected }\end{array}$ & $\begin{array}{c}\text { Visit } 1 \\
\text { (Enrolment } \\
\text { Visit) }\end{array}$ & $\begin{array}{c}\text { Visit X } \\
\text { (Dose } \\
\text { Titration) }\end{array}$ & $\begin{array}{l}\text { Visit } 2 \text { at } \\
\text { Discharge }\end{array}$ & $\begin{array}{c}\text { Visit } 3 \\
\text { (Telephone } \\
\text { Visit) } \\
\end{array}$ & $\begin{array}{l}\text { Visit } 4 \\
\text { (Telephone } \\
\text { Visit) }\end{array}$ \\
\hline Visit window & $\sim-7$ Days & & \pm 3 Days & \pm 3 Days & \pm 3 Days \\
\hline $\begin{array}{c}\text { Inclusion/ exclusion } \\
\text { criteria } \\
\end{array}$ & $\mathrm{X}$ & & & & \\
\hline $\begin{array}{c}\text { Patient Informed } \\
\text { Consent } \\
\end{array}$ & $\mathrm{X}$ & & & & \\
\hline Dose of metoprolol & $\mathrm{X}$ & & $\mathrm{X}$ & $\mathrm{X}$ & $\mathrm{X}$ \\
\hline $\begin{array}{c}\text { Dose adjustment of } \\
\text { metoprolol }\end{array}$ & & $X$ & & $X$ & $X$ \\
\hline $\begin{array}{c}\text { Systolic/diastolic } \\
\text { blood pressure, heart } \\
\text { rate }\end{array}$ & $\mathrm{X}$ & $\mathrm{X}$ & $\mathrm{X}$ & $X$ & $\mathrm{X}$ \\
\hline $\begin{array}{c}\text { Transient } \\
\text { exacerbation }\end{array}$ & & & $X$ & & \\
\hline $\begin{array}{c}\text { Demographic } \\
\text { information }\end{array}$ & $\mathrm{X}$ & & & & \\
\hline Medical History & $\mathrm{X}$ & & & & \\
\hline ECG & $\mathrm{X}$ & & & & \\
\hline Vital signs & $\mathrm{X}$ & $\mathrm{X}$ & & & \\
\hline $\begin{array}{c}\text { Clinical } \\
\text { manifestation }\end{array}$ & $\mathrm{X}$ & & & & \\
\hline $\begin{array}{l}\text { Haematological } \\
\text { examination }\end{array}$ & $\mathrm{X}$ & & & & \\
\hline Serum chemistry & $X$ & & & & \\
\hline $\begin{array}{c}\text { Echocardiography: } \\
\text { LVEF }\end{array}$ & $\mathrm{X}$ & & & & \\
\hline $\begin{array}{l}\text { Other non-drug } \\
\text { therapy (e.g., PCI) }\end{array}$ & $X$ & & & & \\
\hline $\begin{array}{c}\text { Concomitant } \\
\text { medication }\end{array}$ & $X$ & $\mathrm{X}$ & $\mathrm{X}$ & $\mathrm{X}$ & $X$ \\
\hline $\begin{array}{c}\text { Enrolled and } \\
\text { recorded }\end{array}$ & $\mathrm{X}$ & & & & \\
\hline $\begin{array}{c}\text { Adverse Events / } \\
\text { Serious Adverse } \\
\text { Events }\end{array}$ & $X$ & $\mathrm{X}$ & $\mathrm{X}$ & $\mathrm{X}$ & $X$ \\
\hline
\end{tabular}

Figure 2 Baseline information on the trial process chart.

$\mathrm{Hg}$, no symptoms and signs of acute heart failure. When these evaluation parameters are met, the dose can be increased. The specific dose increase is determined by the investigator based on their clinical experience. After 48 hours, the evaluation will be performed every day and the dose is increased when appropriate.

The titration of metoprolol will be based on the ACCF/ AHA guidelines. ${ }^{4}$ As represented in figure 3, metoprolol tartrate, $25 \mathrm{mg}$ and metoprolol succinate, $47.5 \mathrm{mg}$ will be prescribed to all patients without any randomisation every $6-12$ hours within the first 48 hours after admission. Then, after 48 hours, the dose of the metoprolol was increased with daily dosing of 90-190 mg metoprolol. The dose will be decreased when the patient is not tolerated, and patients may be discontinued when necessary. No drugs will be provided after the study. However, patients should continue the $\beta$-blocker treatment based on doctors' prescription and follow the guidelines recommendation.

\section{Study outcomes}

Primary endpoints

The percentage of ACS patients achieving target dose at the time of discharge. (Target dose definition: patient receiving metoprolol succinate $95 \mathrm{mg}$ /day or greater at discharge; or metoprolol succinate under $95 \mathrm{mg}$ /day but reached maximum tolerate dose while experiencing any intolerance sign such as HR under 50 beats/min or BP under $90 / 60 \mathrm{~mm} \mathrm{Hg}$ during hospitalisation and so on.) The dosing pathway is considered feasible when the 
Regimen for dose adjustment of metoprolol in ACS

\begin{tabular}{|c|c|c|c|c|}
\hline Admission & \multicolumn{2}{|c|}{ After 48 h } & \multicolumn{2}{|c|}{ After discharge } \\
\hline $\begin{array}{l}\text { No contraindications } \\
\text { in ACS patients ( } \mathrm{PCl} \\
\text { or non-PCI patients, } \\
\text { including } \\
\text { STEMI/NSTE ACS) }\end{array}$ & $\begin{array}{l}\text { Metoprolol fast release } \\
25 \mathrm{mg}-50 \mathrm{mg} \mathrm{q6}-12 \mathrm{~h}\end{array}$ & $\begin{array}{l}\text { Re-evaluation of risk, no } \\
\text { contraindication and tolerated, } \\
\text { switch to metoprolol control } \\
\text { release } 95 \mathrm{mg}-190 \mathrm{mg} \text { qd }\end{array}$ & $\begin{array}{l}\text { Adjust the dose of metoprolol } \\
\text { control release to the maximum } \\
\text { tolerated dose }\end{array}$ & $\begin{array}{l}\text { Titrate the dose to max } \\
\text { tolerated dose if dose } \\
\text { does not meet the } \\
\text { targeted dose }\end{array}$ \\
\hline
\end{tabular}

\begin{abstract}
Evaluation of tolerability
Evaluation timing: prior to administration in the first $48 \mathrm{~h}$, daily after $48 \mathrm{~h}$, increase the dose when appropriate Evaluation parameter: rest heart rate $\geq 45$ beats/min and without symptomatic bradycardia, systolic blood pressure $\geq 100 \mathrm{mmHg}$, no symptoms and signs of acute heart failure.
\end{abstract}

Figure 3 Dose titration of metoprolol to be followed in the study. ACS, acute coronary syndrome.

percentage of patients who reach the target dose at the time of discharge is around $80 \%-90 \%$.

\section{Secondary endpoints}

Determining the mean HR and BP at discharge and during the follow-up period of the patients who have achieved target dose at discharge. In the acute phase, BP will be monitored using electronic BP device supplied by the CardioCloud Medical Technology, Beijing Co. These devices will be calibrated before first use and regularly calibrated every month. After acute phase, ECG will be used to collect HR before discharge. Before discharge, patients would be taught to use the electronic BP device. After discharge, patients will self-monitor their HR and $\mathrm{BP}$ and record in the logbooks. If the average is lower than the standard, the result will be recorded as bradycardia or hypotension. During hospitalisation and after discharge, the resting HR and BP will be assessed three times a day.

We will also record the percentage of patients who experience bradycardia (HR under 50 beats/min), hypotension (BP under $90 / 60 \mathrm{~mm} \mathrm{Hg}$ ) and drug-related temporary heart failure worsening (based on New York Heart Function Assessment (NYFA)) during hospitalisation and for 1 month after discharge, respectively. Also, the percentage of patients with metoprolol-related AEs and number and kinds of metoprolol-related AEs leading to metoprolol discontinuation will also be assessed.

The temporary heart failure worsening will be determined by clinicians based on the Chinese guidelines for the diagnosis and treatment of heart failure and the NYHA.

\section{Safety endpoints}

Safety endpoints will focus on a composite of possible situations of intolerability (rest $\mathrm{HR}<45$ beats/min and symptomatic bradycardia, systolic $\mathrm{BP}<100 \mathrm{~mm} \mathrm{Hg}$, and symptoms and signs of acute heart failure).

\section{Safety variables}

Adverse events

An $\mathrm{AE}$ is the development of an undesirable medical condition or the deterioration of a pre-existing medical condition following or during exposure to a pharmaceutical product. An AE may or may not have a causal relationship with the drug or treatment. AEs include those occurring at any time after the patient signs the ICF and is recruited into the study. When an $\mathrm{AE}$ is considered probably or possibly related with the medication, dose reduction or drug discontinuation may be considered if necessary.

For over dose: based on the package insert adults receiving metoprolol over $1.4 \mathrm{~g}$ could cause moderate intoxication. Therefore, in this study, metoprolol dose over $1.4 \mathrm{~g} /$ day is considered as over dose. An overdose with associated AEs is recorded as the AE diagnosis/symptoms on the relevant $\mathrm{AE}$ modules in the case report form (CRF) and on the overdose CRF module. An overdose without associated symptoms is only reported on the overdose CRF module.

\section{Serious adverse events}

In the current study, the investigator will assess causal relationship between metoprolol and each AE.

For SAEs causal relationship will also be assessed for other concomitant medication and study procedures. For SAEs that is associated with any study procedure, there is an associated causal relationship. The SAEs will be categorised as mild, moderate and severe.

\section{Archiving of adverse event files}

All AEs occurring during the study will be recorded in the patient's CRF. For all events, details such as the beginning and end of their occurrence, intensity, measures taken and results and so on will be described. The development of existing ischaemia or death from vascular cause should be considered as disease progression and 
not an AE. Events, which are unequivocally due to disease progression including hospitalisation or death caused by ACS, heart failure or arrhythmia and so on should not be reported as an AE.

\section{Safety reporting}

All SAEs have to be reported, irrespective of its causal relationship to the investigational product, or to the study procedure(s). Any SAE occurring during the course of the study, should be informed to the sponsor immediately, not later than 24 hours of when he or she becomes aware of it.

For fatal or life-threatening AEs where important or relevant information is missing, active follow-up is undertaken immediately.

The investigator is responsible for reporting SAEs to the Ethics Committee and/or regulatory authorities according to the local laws and regulations.

\section{Data analysis}

\section{Sample size justification}

This is a study to investigate the percentage of patients achieving target dose during hospitalisation. Assuming the percentage of patients achieving target dose during hospitalisation to be around $80 \%-90 \%, 1000$ patients will allow it to be estimated with a precision (ie, half-length of $95 \% \mathrm{CI}$ ) of $2.5 \%$ to $1.9 \%$. A simple formula ${ }^{14}$ can be used for sample size calculation for the study estimating population prevalence as follows:

$$
n=\frac{Z^{2} P(1-P)}{d^{2}}
$$

where $n=$ sample size, $Z=Z$ statistic for a level of confidence $(Z=1.96$ for $95 \% \mathrm{CI}), P=$-expected prevalence or proportion, $d=$ precision.

\section{Statistical and analytical plans}

A comprehensive statistical analysis plan will be prepared before database lock. All the patients who receive at least one dose of study drug, and for those any post dose data are available will be included in the full analysis set. It will be used for all analyses. Statistical methods will be primarily descriptive in nature. Descriptive statistics will be used for analysing primary and secondary outcomes. The continuous data will be presented as number of patients (n), mean, SD, median, minimum and maximum. The categorical data will be expressed as frequency and percentage of patients in each category. Counts that are zero will be displayed as ' 0 '. Percentages will be based on non-missing data unless otherwise specified. 95\% CI will be calculated if appropriate.

A subgroup analysis of the secondary endpoints may be performed for patients achieving target dose or not, respectively. Statistical analyses will be performed using SAS. A p value of $<0.05$ will be used to indicate statistical significance.

\section{Patient and public involvement}

Members of the ethics committee reviewed this study and made constructive comments, which have been addressed.
Patients were not involved in the recruitment or conduct of the study. All patients provided full informed consent, with at least 24 hours to consider the information and at least two opportunities to discuss the trial in detail with the investigators. The results of the study will be disseminated to all study patients at the end of the trial.

\section{DISCUSSION}

Though $\beta$-blockers are recommended by major international guidelines in the management of ACS, it has remained an underused therapy. ${ }^{15}$ The different international guidelines have demonstrated an improved trend towards initiation and maintenance of $\beta$-blockers therapy; however, the dosages of $\beta$-blockers prescribed in clinical practice are lesser than the dosages prescribed in clinical trials or those recommended in guidelines. ${ }^{16}$ Through this study, we intend to assess the feasibility and tolerability of metoprolol optimal dosing pathway in Chinese ACS patients by observing the percentage of patients achieving target dose during hospitalisation for ACS.

The results of our study will determine the metoprolol optimal dosing pathway, at different hospital sites that will lead to utilisation of $\beta$-blockers in higher dosages, thereby resulting in an improved HR.

$\beta$-blockers lowers the resting HR and systemic arterial pressure and hence the myocardial contractility is decreased which in turn reduce the myocardial oxygen demand and the occurrence of ventricular arrhythmias. ${ }^{17}$

Evidences from previous studies have identified suboptimal doses of $\beta$-blockers prescribed in patients with ACS. ${ }^{418}$ A previous study investigated the use of $\beta$-receptor blocker in patients with CHD in 24 hospitals in Beijing and found that the average dose was only about $40 \mathrm{mg} /$ day, ${ }^{13}$ and the China-PEACE study indicated that $<5 \%$ patients received $>50 \mathrm{mg}$ metoprolol. ${ }^{12}$ In our study, we will be initiating metoprolol fast release at a dose of 25-50 mg every 6-12 hours for the first 48 hours of hospitalisation. After 2 days if the drug is well-tolerated, it be slowly switched to control release metoprolol at a dose of 95-190 mg once a day. The patients at discharge will be advised to continue at the maximum tolerated dose of control release metoprolol. Based on current clinical practice, if the percentage of patients who reach the target dose at the time of discharge is around $80 \%-90 \%$, the dosing pathway is considered feasible.

The study by Butler et alevaluating the outpatient adherence to $\beta$-blocker therapy post-myocardial infarction, reported a significant decrease in use of $\beta$-blockers after discharge. ${ }^{19}$ The titration of medications is often very low in the outpatient setting; hence, it is important to initiate and optimise $\beta$-blocker therapy to achieve recommended target HRs. In our study, the patients at discharge will be advised to continue the maximum tolerated dose and we will be assessing the maximum continued tolerated dose of metoprolol and the associated HRs and BP after 4 weeks of discharge. A 1 month follow-up was designed for patient safety considerations, 
taking into account the dose adjustment after discharge and the collection of safety indicators.

Patients will self-monitor their $\mathrm{HR}$ and $\mathrm{BP}$ after discharge, which may result in errors. However, most of the patients come from out-of-town, and face-toface follow-up is difficult to achieve, so the patient selfmonitoring will be adopted. Nevertheless, the patients will be educated before discharge from the hospital to use the electronic sphygmomanometer provided by Cardiocloud Medical Technology (Beijing) Co., Ltd. for self-monitoring of BP. Calibration will be performed on discharge if the patient has a home $\mathrm{BP}$ monitor.

The guideline applied in practice initiative to measure the effects of a quality improvement project on adherence to evidence-based therapies for patients with AMI had demonstrated quality improvement among the hospitals, patients and caregivers. ${ }^{20}$

Standardised clinical pathways including the drug optimising pathways will help the physicians to appropriately manage their patients and also to reinforce the key quality goals. Further, it is imperative to improve awareness of agents that have proven mortality benefits such as metoprolol. The results of our study will highlight the optimal dosing of metoprolol in Chinese ACS patients thereby promoting increased utilisation.

Acknowledgements The authors acknowledge Dr Amit Bhat and Dr Dhanya (Indegene Pvt Ltd, Bangalore) for providing necessary writing assistance and editorial support towards the development of the manuscript.

Contributors DL and YC conceived and designed the study. WD drafted the grant proposal. DL and YC drafted the protocol presented. YL, JW, YM and HZ provided methodological and statistical support. DL, YD, WD, JW and SZ are responsible for study management. All authors critically reviewed and approved the final version of the manuscript.

Funding This work was supported by the National Key Research and Development Program of China (2016YFC1300300).

Competing interests None declared.

Patient consent for publication Informed written consent is obtained from the participant before any study specific procedures are performed. We will not disclose individual results. To protect privacy and confidentiality, approval for the linkage of the data is provided under strict conditions for the storage, retention and use of the data.

Ethics approval This study protocol was reviewed and approved by Ethics committee of the Chinese PLA General Hospital (the committee's reference number: S2017-112-01). The investigator should timely report to the Ethics Committee any additional changes to the study protocol and any serious adverse events that have occurred during the trial, as they may affect the safety of the subjects and the conduct of the study. The results will be presented at international scientific meetings and through publications in peer-reviewed journals.

Provenance and peer review Not commissioned; externally peer reviewed.

Open access This is an open access article distributed in accordance with the Creative Commons Attribution Non Commercial (CC BY-NC 4.0) license, which permits others to distribute, remix, adapt, build upon this work non-commercially, and license their derivative works on different terms, provided the original work is properly cited, appropriate credit is given, any changes made indicated, and the use is non-commercial. See: http://creativecommons.org/licenses/by-nc/4.0/.
REFERENCES

1 Kumar A, Cannon CP. Acute coronary syndromes: diagnosis and management, part I. Mayo Clin Proc 2009;84:917-38.

2 Zhao R, Xu K, Li Y, et al. Percutaneous coronary intervention in patients with acute coronary syndrome in Chinese military hospitals, 2011-2014: a retrospective observational study of a national registry. BMJ Open 2018;8:e023133.

3 Moran A, Gu D, Zhao D, et al. Future cardiovascular disease in China: Markov model and risk factor scenario projections from the coronary heart disease policy model-china. Circ Cardiovasc Qual Outcomes 2010;3:243-52.

4 O'Gara PT, Kushner FG, Ascheim DD, et al. 2013 ACCF/AHA guideline for the management of ST-elevation myocardial infarction: a report of the American College of cardiology Foundation/American heart association Task force on practice guidelines. J Am Coll Cardiol 2013;61:e78-140.

5 Amsterdam EA, Wenger NK, Brindis RG, et al. 2014 AHA/ACC guideline for the management of patients with non-ST-elevation acute coronary syndromes: a report of the American College of Cardiology/American heart association Task force on practice guidelines. J Am Coll Cardiol 2014;64:e139-228.

6 Hjalmarson A, Elmfeldt D, Herlitz J, et al. Effect on mortality of metoprolol in acute myocardial infarction. A double-blind randomised trial. Lancet 1981;2:823-7.

7 Dargie HJ. Effect of carvedilol on outcome after myocardial infarction in patients with left-ventricular dysfunction: the Capricorn randomised trial. Lancet 2001;357:1385-90.

8 de Matos Soeiro A, de Barros E Silva PGM, Roque EAdeC, et al. Mortality reduction with use of oral beta-blockers in patients with acute coronary syndrome. Clinics 2016;71:635-8.

9 Bradford WD, Chen J, Krumholz HM. Under-utilisation of betablockers after acute myocardial infarction. pharmacoeconomic implications. Pharmacoeconomics 1999;15:257-68.

10 China Society of Cardiology of Chinese Medical Association, Editorial Board of Chinese Journal of Cardiology, China Society of Cardiology of Chinese Medical Association Editorial Board of Chinese Journal of Cardiology. [Guideline on the diagnosis and therapy of ST-segment elevation myocardial infarction]. Zhonghua Xin Xue Guan Bing Za Zhi 2015;43:380-93.

11 Jiang J, Cong $\mathrm{H}$, Zhang $\mathrm{Y}$, et al. Effect of metoprolol succinate in patients with stable angina and elevated heart rate receiving lowdose $\beta$-blocker therapy. Int J Med Sci 2017;14:477-83.

12 Zhang $\mathrm{H}$, Masoudi FA, Li J, et al. National assessment of early $\beta$-blocker therapy in patients with acute myocardial infarction in China, 2001-2011: The China Patient-centered Evaluative Assessment of Cardiac Events (PEACE)-Retrospective AMI Study. Am Heart J 2015;170:506-15.

13 Li D, Dong W, Chen Y, et al. [Effect of pathway training on rest heart rate and the application of $\beta$-blocker in coronary heart disease patients: an open-label, multi-center, prospective study]. Zhonghua Yi Xue Za Zhi 2015;95:2272-6.

14 Pourhoseingholi MA, Vahedi M, Rahimzadeh M. Sample size calculation in medical studies. Gastroenterol Hepatol Bed Bench 2013;6:14-17.

15 Fonarow GC. Beta-Blockers for the post-myocardial infarction patient: current clinical evidence and practical considerations. Rev Cardiovasc Med 2006;7:1-9.

16 Viskin S, Kitzis I, Lev E, et al. Treatment with beta-adrenergic blocking agents after myocardial infarction: from randomized trials to clinical practice. J Am Coll Cardiol 1995;25:1327-32.

17 Irani F, Herial N, Colyer WR. Impact of an acute coronary syndrome pathway in achieving target heart rate and utilization of evidencebased doses of beta-blockers. Am J Ther 2012;19:397-402.

18 Kukin A, Noel ZR, Watson K. Through the decades: $\beta$-blocker use and outcomes in acute coronary syndromes. Cardiol Rev 2018;26:157-66.

19 Butler J, Arbogast PG, BeLue R, et al. Outpatient adherence to betablocker therapy after acute myocardial infarction. J Am Coll Cardiol 2002;40:1589-95.

20 Mehta RH, Montoye CK, Gallogly M, et al. Improving quality of care for acute myocardial infarction: the guidelines applied in practice (GAP) initiative. JAMA 2002;287:1269-76. 